\title{
Engaging shoppers through mobile apps: the role of gamification
}

\author{
Francesca De Canio \\ Department of Economics Marco Biagi, University of Modena and Reggio Emilia, \\ Modena, Italy \\ Maria Fuentes-Blasco ${ }^{(1)}$ \\ Department of Management and Marketing, Pablo de Olavide University, \\ Sevilla, Spain, and \\ Elisa Martinelli \\ Department of Economics Marco Biagi, University of Modena and Reggio Emilia, \\ Modena, Italy
}

\begin{abstract}
Purpose - The purpose of this paper is to examine the influence of several intrinsic motivations driving consumers' intention to buy using a mobile app, namely: shopping gamification, focussed attention, shopping enjoyment and socialness, through the mediating role of shopping engagement. The online shopping experience is investigated in its dual role as direct driver of the intention to buy using a mobile app and as moderator of the shopping engagement - intention to buy using a mobile app path.

Design/methodology/approach - The empirical analysis was performed in China due to the extensive usage of mobile shopping apps amongst the Chinese population. A structural equation model was estimated on 893 valid and complete structured questionnaires collected amongst a sample of Chinese consumers.

Findings - Findings confirm that intrinsic motivations (i.e. shopping gamification, focussed attention, shopping enjoyment and socialness) indirectly influence the intention to buy using a mobile app channelled by shopping engagement. Most remarkably, results show that the online shopping experience positively moderates the shopping engagement - intention to buy using a mobile app path.

Originality/value - The novelty of the paper lies in the conceptual and empirical evidence provided on shopping gamification, within the retailing marketing domain. The study investigates other related intrinsic motivations that jointly with shopping gamification directly influence shopping engagement and indirectly impact mobile shopping intention. The paper provides insights into the moderating role of online shopping experience, a key aspect when the challenge concerning gamification is considered.
\end{abstract}

Keywords Mobile shopping, Engagement, Gamification, Previous online shopping experience

Paper type Research paper

(C) Francesca De Canio, Maria Fuentes-Blasco and Elisa Martinelli. Published by Emerald Publishing Limited. This article is published under the Creative Commons Attribution (CC BY 4.0) licence. Anyone may reproduce, distribute, translate and create derivative works of this article (for both commercial and non-commercial purposes), subject to full attribution to the original publication and authors. The full terms of this licence may be seen at http://creativecommons.org/licences/by/4.0/legalcode

Francesca De Canio and Elisa Martinelli did not receive any specific grant from funding agencies in the public, commercial or non-for-profit sectors. Maria Fuentes-Blasco acknowledges the financial support from SEJ-601 “(IMEGS)".

Although the paper is the result of the collaborative work of the three authors, Francesca De Canio developed the introduction, gamification, literature review and hypotheses, data curation, limitations and directions for further research sections (contribution: ca. 45\%); Maria Fuentes-Blasco developed the methodology and results sections (contribution: ca. 35\%); Elisa Martinelli cared the conclusion and implications section (contribution: ca. 20\%).

Shopping and Gamification

Received 16 September 2020

Revised 24 December 2020 12 February 2021

Accepted 26 February 2021 
IJRDM

49,7

920

\section{Introduction}

The pervasive, interactive and ubiquitous technology is opening up the debate on how to use ICT to improve the retailer-customer relationship to enhance the shopping experience (Caboni and Hagberg, 2019). The introduction of in-store digital tools such as QR codes, virtual screens, shelves and isles, self-service kiosks, self-scanning machines (Piotrowicz and Cuthbertson, 2014; Siregar and Kent, 2019), as well as the integration of augmented virtual elements (Caboni and Hagberg, 2019; Flavián et al., 2019), may influence the in-store shopping experience. Likewise, gamification and social cues may enhance the online shopping experience (Insley and Nunan, 2014; Rodrigues et al., 2016).

The literature agrees that the emerging interactive technologies and the increased usage of digital platforms can make the experience more engaging and consumers more loyal with positive effects on retailers' profitability (Rodrigues et al., 2016). Extrinsic and intrinsic motivations jointly determine consumers' shopping intentions (O'Brien, 2010; Van der Heijden, 2004). Nevertheless, retailers' strategies based on pricing and/or product innovation, prevailing so far, are no more sufficient (Insley and Nunan, 2014). Companies marketing strategies are increasingly incorporating the fast-emerging trend to gamification (Yang et al., 2017). Gamification generated an estimated value of $\$ 5.5 \mathrm{bn}$ in 2018 with a $600 \%$ potential increase in user's downloading for gamified business apps (Lynkova, 2019). From a theoretical perspective, gamification is becoming a relevant research topic being a driver for experiential aspects (i.e. enjoyment, engagement and retention) of the user-platform interaction (Hamari, 2013; Hofacker et al., 2016). The introduction of gamified, ludic and social elements in mobile apps reduces consumers' cognitive efforts (Rodrigues et al., 2016), representing a potential competitive advantage for retailers. Our paper aims at contributing to the retailing and marketing literature, with a specific focus on mobile retailing apps, investigating how intrinsic - social and motivational - cues, namely: shopping gamification, focussed attention, shopping enjoyment and socialness, influence shopping engagement (Van Doorn et al., 2010). Shopping engagement is investigated as a predictor of consumer's intention to buy using a mobile app. Furthermore, the paper explores the bivalent nature of the online shopping experience as direct driver (Goldstein and Gigerenzer, 2002) and moderator (Giovanis et al., 2018) of consumers' intention to buy using a mobile app.

The empirical analysis was conducted in China, the country with the worldwide largest and long-lived tradition in the game industry (Fang, 2019) and in the use of smartphones and mobile apps. In the country, smartphones penetration reached $53 \%$ of the overall population, and almost $70 \%$ of smartphones have installed shopping apps (China Internet Watch, 2019). Further, China is experiencing the spread of multifunctional apps, such as WeChat (Wêixin), amongst others, allowing together modern social networking and m-commerce (TenPay-Cai $\mathrm{Fu}$ Tong).

Three are the main contributions of this study. First, in response to the literature that considers price convenience and product innovation as necessary but no longer sufficient to drive consumers' buying intentions, the paper examines how intrinsic motivations (i.e. shopping gamification, focussed attention, shopping enjoyment and socialness) influence consumer engagement. Second, the study explores the bivalent role of previous online shopping experience as direct driver of the consumers' intention to buy using a mobile app, and as moderator of the shopping engagement-intention to buy path. The third and most innovative contribution of the paper concerns the conceptualization and empirical evidence of the role played by gamification in enhancing, directly, shopping engagement and, indirectly, buying intentions towards mobile retailing apps. Gamification is assuming a key role in recent marketing strategies (Hamari et al., 2014), although its purpose has been poorly investigated (Hamari, 2013; Insley and Nunan, 2014). Actually, gamification is fairly recent in marketing studies. Through an overview of its conceptualization along the last decade - since its conceptualization - this paper theoretically defines the gamification concept (Yang et al., 2017), 
contextualising it in the retail domain. Further, the paper responds to the contribution to a death empirical evidence on the effect of gamification in the consumer decision process through digital platforms (Hofacker et al., 2016). Specifically, this research empirically tests the role of shopping gamification in enhancing shopping engagement and indirectly the mobile shopping intention.

The paper is organised as follows. The gamification concept is explored in the next theoretical section. Section 2 presents the hypotheses underpinning the study. The subsequent section presents the empirical analysis. The paper concludes with the main results of the analysis, the key theoretical and managerial implications, and suggestions for possible developments to work out in future studies.

\section{Gamification: from serious games to mobile apps}

Serious games are computer-based software potentiated with game features operating in several non-game contexts, such as education, labour, banking, trading and retailing, amongst others. They provide a more entertaining and engaging user-application interaction. The development of serious games lies in the necessity to reduce the uncertainty related to the usage of unknown technologies and to improve users' intrinsic motivations (Malone, 1981).

Although the origin of serious games is far, only 30 years later, in 2010, the term "gamification" in relation to serious games gained popularity in several industries (Yang et al., 2017). The evolution and adoption of gamification (i.e. the use of game features for nonentertainment purposes - Deterding et al., 2011a, b) goes hand in hand with the evolution and adoption of mobile apps. Gamification refers to the gameful and ludic experience felt by the individual when using an app augmented with game-mechanics. It is usually conceptualised as the use of game design elements in non-game contexts (Deterding et al., 2011a, b). Although gamification is associated with no-gaming activities, the term is often improperly misled with playing games (Robson et al., 2014). It originated from video games design and interfaces. However, whereas "playing denotes a more freeform, expressive, improvisational, even "tumultuous" recombination of behaviours and meanings, gaming captures playing structured by rules and competitive strife toward goals" (Deterding et al., 2011a, b, p. 3). On the one hand, modern mobile apps are developed on previous video game interfaces and possess similar interactive and immersive features (Hsu and Chen, 2018). On the other hand, gamification enhances the customer intrinsic motivation and his/her naturally related behaviour (Gatautis et al., 2016).

Today, all the contexts with high involvement and uncertainty are increasingly flanked by interactive and gamified mechanics to motivate the user to adopt technological tools along the time (Eisingerich et al., 2019). In Table 1, we present the evolution of the gamification concept along the last decade, showing how gamified mechanics can be easily implemented in several marketing domains and how they are becoming increasingly sophisticated and effective in marketing strategies. Gamification influences the customer interaction with the interface and its efficacy concerns not only the customer relationship metrics (e.g. frequencyHerzig et al., 2012; Rodrigues et al., 2016) but also the experiential aspects related to the interaction with a gamified interface such as engagement, enjoyment and flow (Hamari, 2013; Hamari et al., 2014; Yang et al., 2017).

Gamification is gaining more relevance in the literature specifically addressed at studying the usage of interactive technologies to enrich the customer experience (Caboni and Hagberg, 2019; Flavián et al., 2019; Piotrowicz and Cuthbertson, 2014; Siregar and Kent, 2019). Nevertheless, the marketing literature on the topic is still in its infancy (Hamari et al., 2014) and is lacking of empirical evidence (Hamari, 2013; Hofacker et al., 2016; Tobon et al., 2020), above all considering the variety of marketing domains in which gamification may influence the interaction between the interface and the user. 


\begin{tabular}{l} 
IJRDM \\
49,7 \\
$\mathbf{9 2 2}$ \\
\hline
\end{tabular}

Table 1.

Gamification in the marketing domain

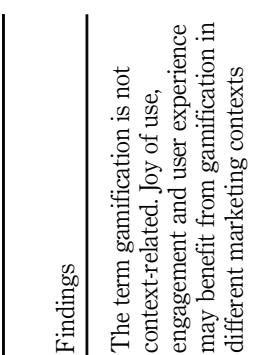

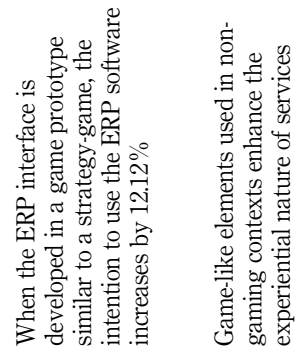

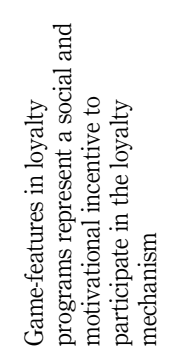

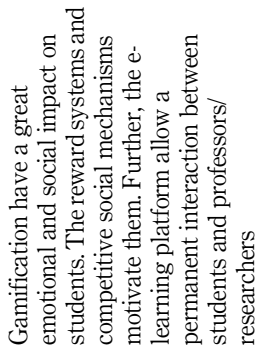

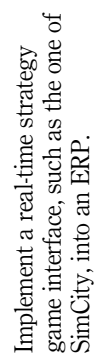

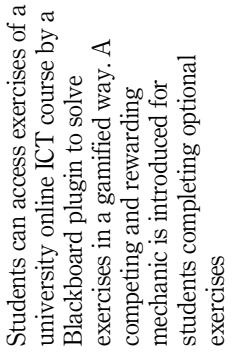

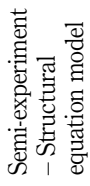

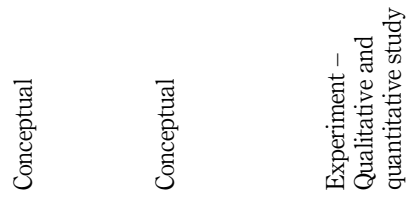

怘

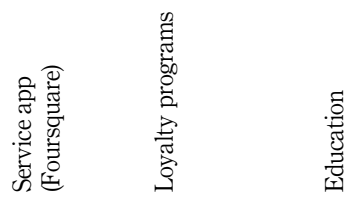

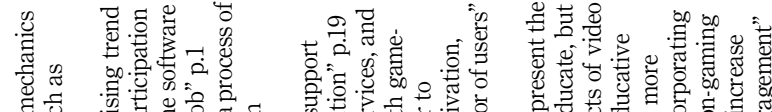

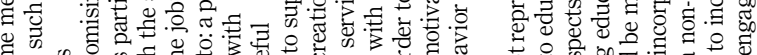

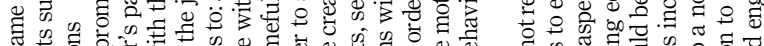

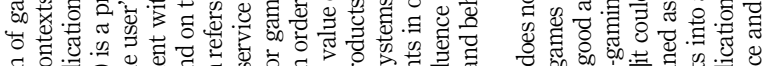

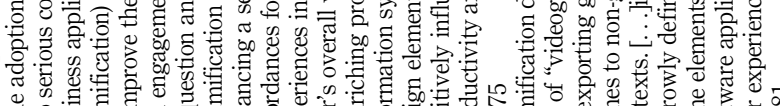

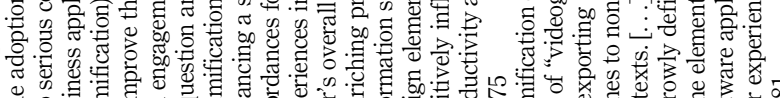

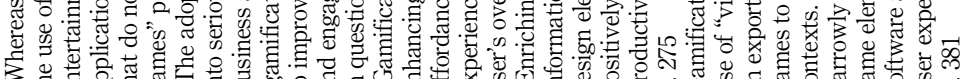

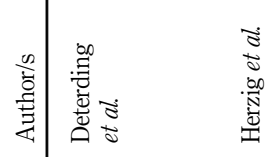

๘

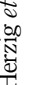

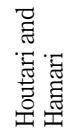

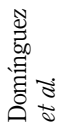

离|

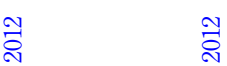

సีำ

꽁

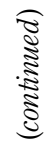




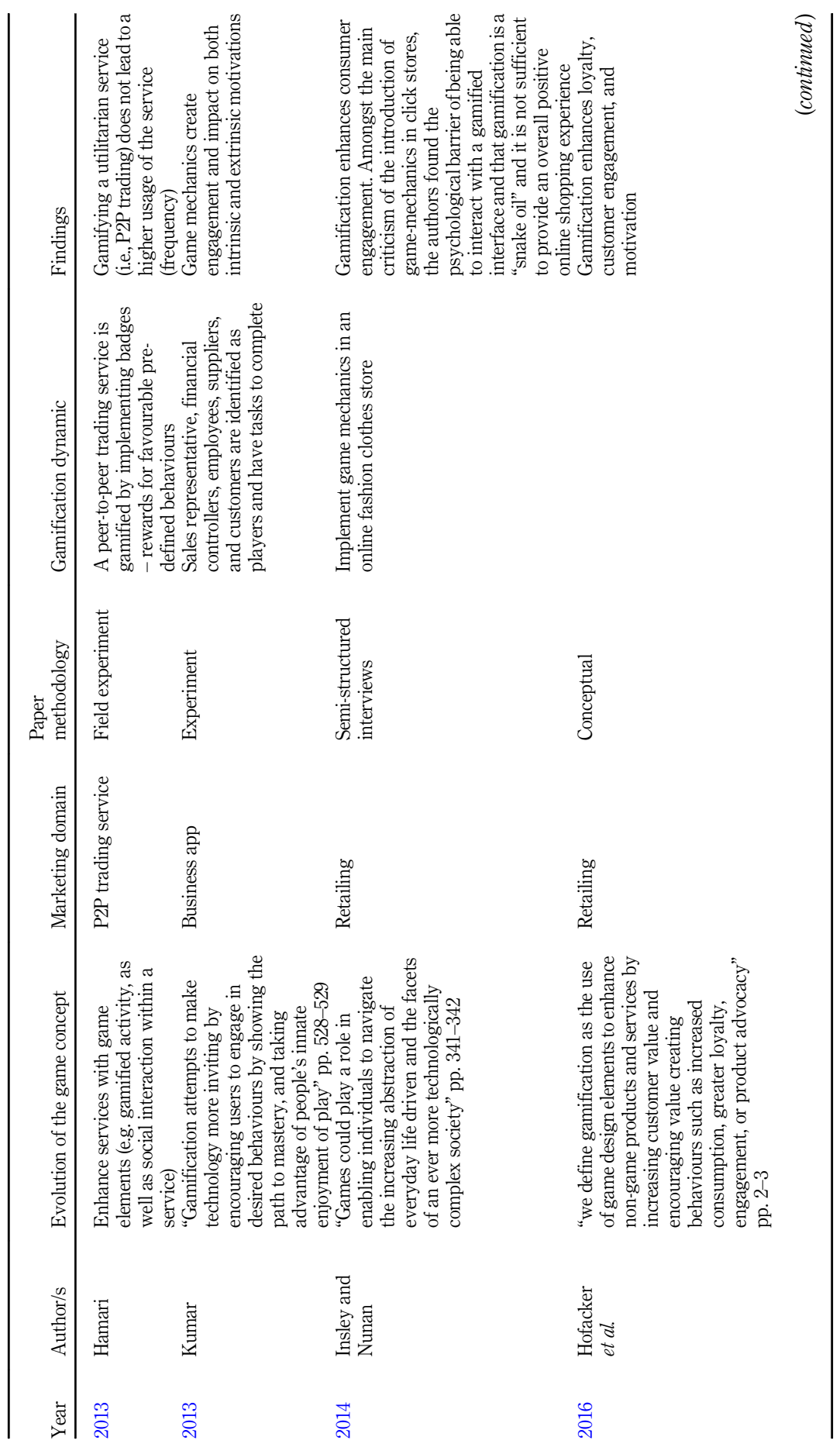

Shopping and

Gamification

923

Table 1. 


\begin{tabular}{l} 
IJRDM \\
49,7 \\
$\mathbf{9 2 4}$ \\
\hline
\end{tabular}

IJRDM

924

\section{|}

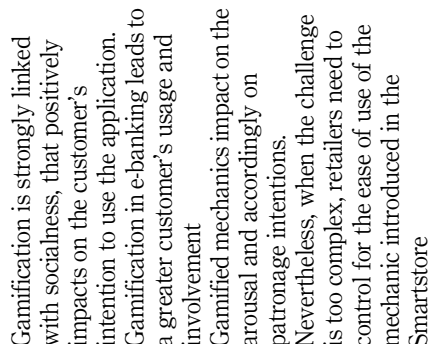

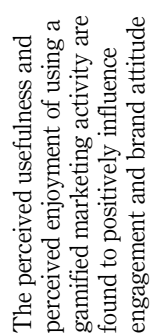

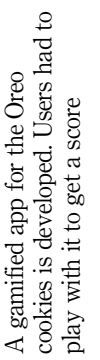

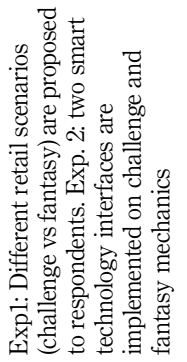

苞

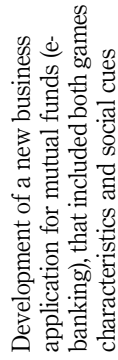

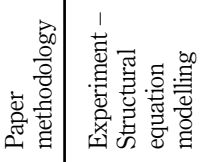

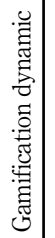

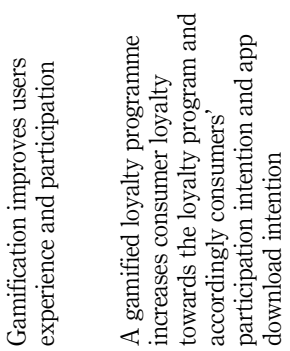

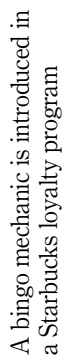

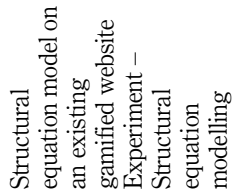

Table 1.

:

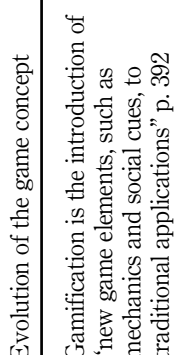

竭

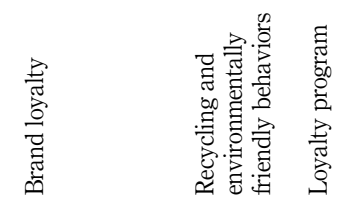

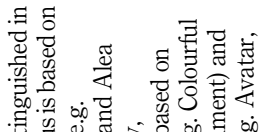

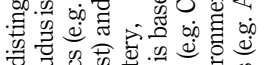

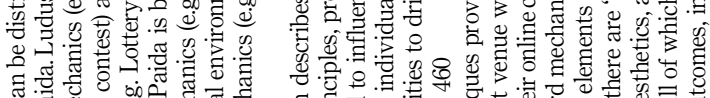
हैं

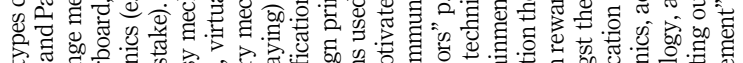

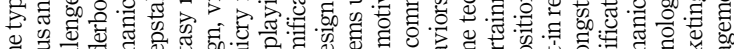

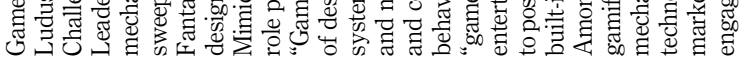

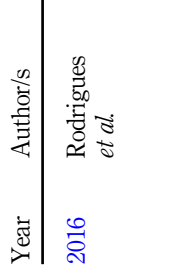

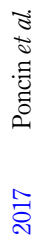

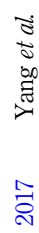

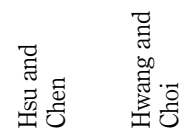

ลี่ $\quad$ ลี่ ลั่ 


\section{Literature review and hypotheses}

The technology acceptance model (TAM - Davis, 1986), revolving from the previous social psychology theories (e.g. theory of reasoned action - TRA - Fishbein and Ajzen, 1980), combines motivation-intention aspects with intrinsic motivations to explain and predict consumers' technology acceptance and usage. Recently, it has been applied to predict the consumer's shopping behaviour in gamified smartstores (Poncin et al., 2017). In the literature review conducted by Tobon $e t$ al. (2020), the authors found TAM to be the most relevant theory used to test empirically the impact of gamification on consumer engagement and shopping intention across several marketing domains.

Based on previous studies, this paper evaluates the main intrinsic motivations underpinning consumer engagement, and accordingly, the intention to use a mobile app. Unlike extrinsic motivations, intrinsic motivations arise simultaneously when consumer engagement occurs (O'Brien, 2010). Then, a mix of intrinsic motivations should be considered (Deterding et al., 2011a, b). To this aim, this paper investigates shopping gamification (Insley and Nunan, 2014), and other related intrinsic motivations, such as focussed attention (O'Brien, 2010), shopping enjoyment and socialness (Rodriegues et al., 2016; Shang et al., 2005).

\section{Shopping gamification (GAME)}

The concept of gamification is fairly new in the retailing context but, as reported above, it has already been studied in related research areas. As highlighted in Table 1, gamification is relevant in enhancing individual motivation and engagement in several contexts. In the advertising literature, Choi et al. noted that "when gamers are cognitively loaded, simply perceiving the stimulus can directly transfer to judgement about the brand" (2013, p. 998). Thus, gamification affects consumers' commitment towards the promoted brand. The role of gamified mechanics consists in generating positive experiences for the user engaged in an activity (Fullerton, 2014). Indeed, a gameful experience is immersive and engaging (Seaborn and Fels, 2015). We consequently postulate the following hypothesis:

H1. Shopping gamification positively affects shopping engagement.

\section{Focussed attention (FA)}

Playing video games, individuals experience a sense of flow (Webster and Martocchio, 1995), which results in higher involvement in the task (Arnold and Reynolds, 2003; Webster and Martocchio, 1995). Focussed attention, also called flow state, represents the individual temporal and environmental dissociation derived by the total absorption in the performed task (Blazquez-Cano et al., 2017). Both concepts express a cognitive absorption in which consumers' "awareness is narrowed to the activity itself" (Hsu and Lu, 2004, p. 856). Focussed attention represents one of the main elements of hedonic perception behind user engagement (Trevino and Webster, 1992). Aspects such as intrinsic interest, curiosity, focussed attention and intense concentration are strongly related to engagement (Agarwal and Karahanna, 2000). Thus, for example, in the business apps context, Herzig et al. (2012) found that flow has a strong positive effect on engagement, which is leading us to posit the following hypothesis:

H2. Focussed attention positively affects shopping engagement.

\section{Shopping enjoyment (ENJ)}

Perceived enjoyment was first introduced into the TAM by Davis (1986). According to Davis et al. "the activity [to use] technology is perceived to be enjoyable in its own right" (1992, p. 1113). At first, the role of enjoyment was studied in connection with computer games (Holbrook et al., 1984; Malone, 1980). Nowadays, a number of studies aimed at investigating
Shopping and Gamification 
IJRDM

49,7

926

the role of perceived enjoyment in other contexts, such as communication, loyalty programmes or shopping, amongst others arise. Shopping enjoyment can be defined as the state of enjoyment and pleasure determined by the shopping activity. It represents the consumer's positive mood experienced during the shopping task. Accordingly, during the shopping the consumer's buying behaviour is strongly affected by his/her emotional state (Beatty and Ferrell, 1998; Wolfinbarger and Gilly, 2001).

The literature is shedding some light on the role played by shopping enjoyment in the retailing context both offline and online. Thus, for example, mobile apps, with potentiated connectivity and interactivity, are increasingly encountering consumers' need for pleasure and fun (Caboni and Hagberg, 2019; Chong, 2013). Accordingly, shopping enjoyment has a key role in influencing consumers' shopping buying behaviour (Huang et al., 2007), as it has been proved that consumers with a positive mood show higher levels of shopping engagement (De Canio et al., 2019; Higgins 2006; Kim et al., 2013). Consequently, our next hypothesis follows:

H3. Shopping enjoyment positively affects shopping engagement.

\section{Socialness (SOC)}

The spread of technological devices has made communication and social interaction both physical and digital. A number of social networks, online communities, thematic pages, blogs and mobile apps support the online social interaction (Katz and Rice, 2002), making socialization a pillar in the human-computer interaction analysis (Lazar and Preece, 2002). For example, in online games, the opportunity to socialise amongst users was recognised as the driver for the creation of a sense of group participation and membership (Holopainen, 2011). "Interaction is a natural feature of online games that enables users [...] to be entertained" (Lee and Tsai, 2010, p. 602). Its key role is confirmed also in the retailing context, where the opportunity to share the shopping task with relatives and friends is considered relevant to entice purchases (Arnould and Reynolds, 2003). This is even more important in the Chinese context, where a unique multifunctional app is allowing the consumer to buy and interact with relatives simultaneously (e.g. WeChat). For this reason, socialness towards the mobile app exerts a positive effect on shopping engagement, supporting the following hypothesis:

H4. Socialness positively affects shopping engagement.

\section{Shopping engagement (ENG)}

"Engagement has been defined as both the act of emotionally involving users and the state of being in gear and interacting directly with a system" (O'Brien, 2010, p. 345). It represents the ability of technology to captivate users' attention, engendering a sense of community and fun (O'Brien and Toms, 2008). When this concept is applied to consumers interacting with a mobile app, it can be outlined as "a psychological state that occurs by virtue of interactive, cocreative customer experiences with a focal agent/object (e.g., a media)" (Brodie at el., 2011, p. 259). In this study, shopping engagement is conceptualised as developing from customer experiences while browsing through shopping applications on mobile devices (Thakur, 2016). It expresses the motivational experience that allows users to be "involved, occupied and interested in something" (Higgins, 2006, p. 442), determining the consumer's "intensity of attraction to or repulsion from something" (p. 439). This happens when intrinsically motivated individuals have a genuine desire to accomplish with the activity (Yang et al., 2017). Consequently, the motivational force driving an individual at displaying, or not, a particular behaviour, results in a source of experience that could be related to the level of engagement. Consumers' engagement could result in both positive and negative conducts. 
Van Doorn et al. defined customer engagement as a behaviour that goes beyond transactions, explaining it as a "customer's behavioural manifestation that has a brand or firm focus, beyond purchase, resulting from motivational drivers" (2010, p. 254).

Customer engagement expresses the experiential interaction between customers and brands, websites or other objects, and on the other hand, it represents the psychological and motivational state of the relationship (Vivek et al., 2014). Therefore, we define shopping engagement as the state of engagement and commitment that the consumer experiences during the shopping task, able to captivate his/her attention and to engender a sense of selfidentification with the retailer. As found by Lin (2007), web stickiness is related to both positive attitude and commitment concepts that in our analysis are included in the shopping engagement construct. "Strength of engagement contributes to the intensity of the motivational force experience" (Higgins, 2006, p. 439). Consequently, consistently with the motivation-intention path proposed in the TRA (Fishbein and Ajzen, 1980), that hypothesises a direct influence of motivations on intentions, we postulate a direct and positive effect of customer engagement on behavioural intentions, as follows:

H5. Shopping engagement positively affects intention to buy using a mobile app

\section{Previous online shopping experience (EXP)}

In the marketing context, the customer experience has been extensively investigated in relation to products, companies and brands (Siregar and Kent, 2019) and, recently, to online shopping channels (Castañeda et al., 2007). The effect of past behaviours can be divided into frequency effects, in which intentions are formed by the recognition heuristic (Goldstein and Gigerenzer, 2002), and recent effects, where intentions are determined by recent behaviours anchoring-adjustment heuristic effect - (Tversky and Kahneman, 1974). According to the Goal-Direct Behaviour model, the "frequency of past behaviour is a predictor of desires, intentions and behaviour, whereas recency of past behaviour predicts behaviour only" (Perugini and Bagozzi, 2001, p. 80).

The previous online shopping experience expresses the consumer's expertise and knowledge about how to buy online towards both electronic and mobile channels. The more expert and knowledgeable with online shopping platforms the consumer is, the more willing he/she will be to continue to buy online. Accordingly, when the consumer has previous experience with online shopping and knows the online platform (both electronic and mobile), he/she is more prone to buy online (Park and Stoel, 2005).

In extant literature, the previous shopping experience is considered as a moderator of online buying intentions too. Thus, for example, Pappas et al. (2014) found that low and high online experienced shoppers have different intentions to buy grocery products online. In the mobile banking context, Giovanis et al. (2018) showed that customer experience moderates the relationship between the intention to use a mobile banking account and several antecedents such as innovativeness, perceived trust and social influence. Accordingly, we can postulate the following hypotheses:

H6. Previous online shopping experience positively affects intention to buy using a mobile app.

H7. Previous online shopping experience positively moderates the effect of shopping engagement on intention to buy using a mobile app.

Figure 1 presents the overall theoretical model.

Shopping and Gamification 


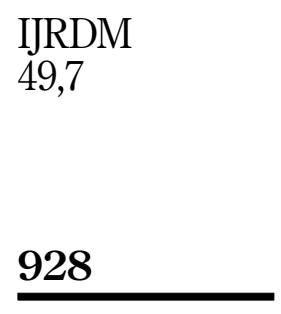

Figure 1.

Theoretical model

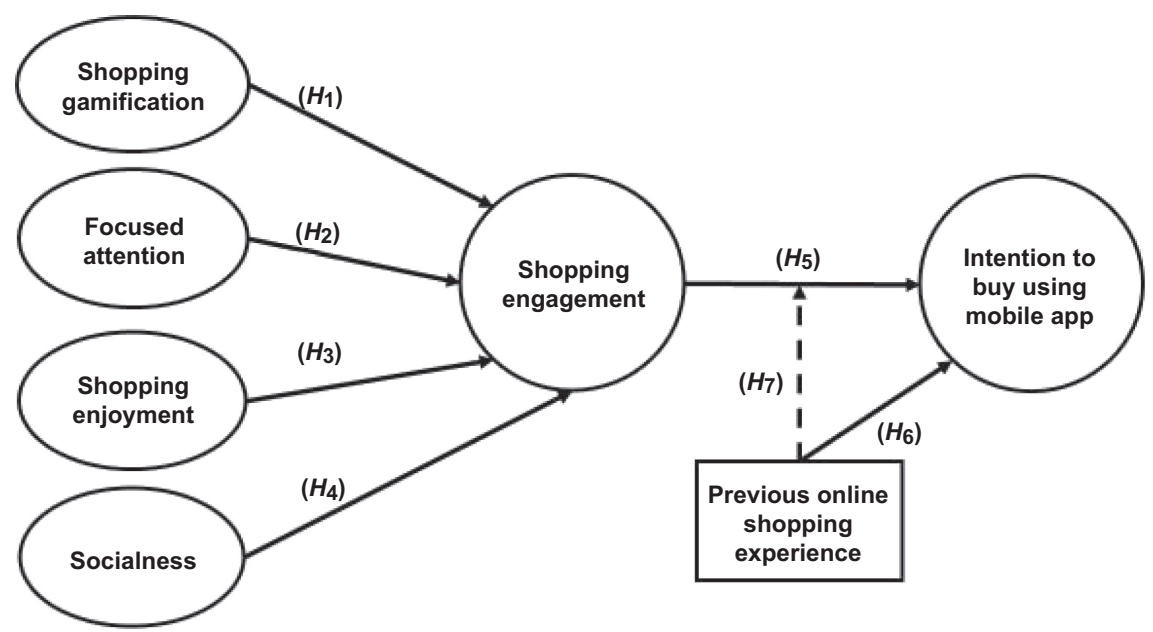

\section{Research methodology}

Measure development and data collection

The quantitative analysis is based on an online survey designed on the SurveyMonkey platform. A structured questionnaire was delivered via WeChat amongst Chinese consumers by means of a snowball sampling. The Chinese context was preferred for the empirical analysis as, differently from other countries (60\% is the average global mobile market-share), in China it reaches a peak of over 80\% (China Internet Watch, 2019). Sharing surveys through social networks allows to intercept the relevant target (Ploll and Stern, 2020). Following the Hsu and Chen (2018) procedure, an existing app incorporating game and social cues was used for the empirical analysis. WeChat was then selected for both sharing the survey with its one billion users, and as setting for the quasi-experimental empirical analysis. "WeChat is used daily by Chinese users for buying goods and services, transferring money, planning holidays [...] and a lot more" (QP Software, 2020). Further, to amplify the overall experience of participating in our study, a Chinese Key Opinion Consumer (KOC) helped us to share the survey link. KOCs are the newest social media influencers in China. KOCs are real consumers who share, with their followers, reviews and opinions on products and services they directly test.

The questionnaire was double translated English-Chinese and Chinese-English to avoid translation bias and to compensate the English literacy weakness featuring the majority of the Chinese population. Items were measured on a 7-point Likert-scale (1: completely disagree -7 : completely agree). Focussed attention (five items) and shopping engagement (three items) were both derived from O' brien and Toms (2013). A six-item scale was used to assess socialness, developed on the study of Arnould and Reynolds (2003). Shopping enjoyment was measured through a six-item scale developed using the previous study of Johnson et al. (2015). Intention to buy using a mobile app was measured through a four-item scale adapted from Overby and Lee (2006). Four items were adapted from Hsu and Chen (2018) to measure shopping gamification. Finally, previous online shopping experience was measured through an item adapted from Novak et al. (2000). The measurement scales are reported in Table 3.

The questionnaire, previously pre-tested on a small sample of respondents, was shared online in January 2019. 903 responses were collected. Responses with missing data were dropped from the dataset. A final dataset of 893 valid and complete questionnaires was used 
for the empirical analysis. 893 surveys were collected with $60.5 \%$ male. Table 2 shows the main demographics of the sample and a list of the main retailers used for their online shopping: Taobao (63\%), Tmall (15\%) and JD.com (12\%) are the most used.

\section{Results}

We applied partial least squares (PLS) structural equation modelling to test our measurement scales dimensionality and hypotheses with Smart PLS v.3.2.9 (Ringle et al., 2015). According to the guidelines provided by Hair et al. (2019), we used a two-step approach to assess the model adequacy. In the first stage, we estimated a measurement model based on principal component-based estimation in order to analyse the dimensionality and validity of our measurement scales (Chin et al., 2013). After, we estimated the structural parameters to test our hypotheses and the explanatory power of our model using 5,000 bootstrap samples. According to Henseler et al. (2009), the use of this level of bootstrapping provides standard errors and $t$-statistics to evaluate the significance of the structural coefficients.

\section{Measurement scales: dimensionality, reliability and validity}

All items were treated as reflective indicators and we evaluate their dimensionality, internal consistency and validity according to the procedures suggested by Hair et al. (2019). With regard to dimensionality, it was necessary to eliminate one item from the shopping enjoyment scale ("I feel like online shopping is a safe place to shop") and two items from the socialness scale ("The links within the online store allow me to move back and forth easily between its different pages" and "Online retailers encourage me to make suggestions and to share my online shopping experience with my relatives, friends and other potential customers") since these items showed a factor loading lower than 0.7. Internal consistency of the dimensions was assessed considering three indicators: Cronbach's alpha indicator exceeded the recommended

\begin{tabular}{lclr}
\hline Gender & $\%$ & Age & $\%$ \\
\hline Male & 60.5 & $18-24$ years & 38.6 \\
Female & 39.5 & $25-35$ years & 51.1 \\
& & $36-50$ years & 9.7 \\
& & $>51$ years & 0.6 \\
Education level & $\%$ & Job & $\%$ \\
Junior high school certificate & 0.6 & Unemployed & 2.6 \\
High school & 9.7 & Part-time worker & 2.6 \\
Bachelor's degree certificate & 71.1 & Student & 18.3 \\
Master's degree & 9.9 & Full-time worker & 76.3 \\
Postgraduate & 8.7 & Pensioner & 0.1 \\
& & Housekeeper & 0.1 \\
Origin & $\%$ & Family & $\%$ \\
1st tier city & Single & 2.7 \\
2nd tier city & 52.7 & Couple & 7.8 \\
3rd tier city & 27.4 & 3 members & 43.3 \\
4th tier city & 10.9 & 4 members & 30.8 \\
Rural area & 4.7 & 5 or more members & 15.4 \\
Main online store & 4.2 & & \\
Taobao & $\%$ & & \\
T-mall & 63.2 & & \\
JD.com & 14.7 & & \\
Amazon & 12.1 & & \\
Vipshop & 3.1 & & \\
Dang Dang & 1.2 & & \\
Alibaba & 1.2 & & \\
Others & 1.0 & & \\
& 3.5 & &
\end{tabular}

Shopping and Gamification
Table 2 . Sample profile 
IJRDM 49,7

threshold of 0.7 (Nunnally and Berstein, 1994), the composed reliability coefficient was greater than 0.7 (Anderson and Gerbing, 1988) and the average variance extracted (AVE) was over 0.5 (Fornell and Larcker, 1981) (Table 3).

Table 3.

Measurement model (scale dimensionality, reliability and validity)

Constructs
Focussed attention (Cronbach's
$\alpha=0.896$
$\mathrm{CR}=0.924$
$\mathrm{AVE}=0.709)$

Shopping enjoyment (Cronbach's $\alpha=0.904$;

$\mathrm{CR}=0.929$;

$\mathrm{AVE}=0.723$

Socialness (Cronbach's $\alpha=0.836$;

$\mathrm{CR}=0.891$;

$\mathrm{AVE}=0.672)$

Shopping gamification (Cronbach's $\alpha=0.919$;

$\mathrm{CR}=0.937$;

$\mathrm{AVE}=0.713)$

Item statements

FA1: I am so involved when I shop online that I lose the track of time

FA2: The time I spend buying online just slips $\quad 0.730 * *$ away

FA3: I lost myself in shopping online

FA4: I block out things around me when I shop online

FA5: When I buy online, I am very absorbed

ENJ1: Shopping online makes me happy

ENJ2: I enjoy shopping online

ENJ3: I find it enjoyable to use online stores for buying products

ENJ4: I found online shopping exciting

ENJ5: Shopping online is funny

SOC3: When I am chatting with friends on social networks I use to switch to online shopping

SOC4: I like to share my online shopping with my friends online

SOC5: Online shopping allows me to socialise my purchases

SOC6: I like shopping online as it allows me to ask suggestions to my friends

GAM1: When I shop online I feel like playing a game

GAM2: I complete several tasks when I shop online

GAM3: Online shopping makes me feel like a winner

GAM4: I like shopping online as it allows me to collect credits like in a game

GAM5: Shopping online is a gamified experience

GAM6: Shopping online is a challenging experience

Shopping engagement (Cronbach's $\alpha=0.779$;

$\mathrm{CR}=0.872$;

$\mathrm{AVE}=0.694)$

Intention to buy using a mobile app

(Cronbach's $\alpha=0.833$;

$\mathrm{CR}=0.888$;

$\mathrm{AVE}=0.666)$

ENG1: My shopping online experience is always rewarding

ENG2: Shopping online is an engaging task

ENG3: I am very committed with online shopping

INTM1: I intend to continue to buy online using a mobile app

INTM2: I intend to increase the frequency of online $0.793^{* *}$ shopping using a mobile app

INTM3: I am willing to recommend others to shop products online using a mobile app

INTM4: It is likely that I will shopping online in

the next month using a mobile app

Previous online shopping experience

Age (control)

Sex (control)

EXP: I have experience about where and how to make purchases online

AGE

SEX

Loading (t-Stat)

$0.849 * *$

$0.730 * * \quad(36.18)$

$0.888 * * \quad(103.39)$

$0.849 * * \quad(66.09)$

$0.885^{* *} \quad(104.88)$

$0.794 * * \quad(34.84)$

$0.840 * * \quad(53.22)$

$0.879 * *$

$0.874 * * \quad(98.76)$

$0.863 * * \quad(79.64)$

$0.740 * * \quad(31.54)$

$0.826 * *$

$0.851^{* *}$

$0.856^{* * *}$

$0.839 * *$

$0.812^{* * *}$

$0.871^{* * *}$

$0.862^{* * *}$

$0.891 * *$

$0.787^{* * *}$

$0.771^{* * *}$

$0.886^{* * *}$

$0.839 * *$

$0.804^{* *}$

$0.823^{* *}$

$0.842^{* * *}$

Note(s): CR: Composite reliability; AVE: Average variance extracted. **: $p<0.01$ 
We confirmed convergent validity as all the reflective indicators showed significant and high standardised loadings (>0.7; t-Stat>2.58) (Steenkamp and Van Trijp, 1991) (Table 3). We checked discriminant validity by linear correlation between each pair of dimensions. These values were less than the square root of the AVE in the scales, showing evidence that each reflective construct related stronger to its own scales than to the others (Table 4).

We analysed this validity in depth with heterotrait-monotrait ratio of correlations. These values, shown in Table 5, were lower than the threshold of 0.9 (Henseler et al., 2015).

\section{Hypotheses testing}

After confirming the validity of the measurement scales, we proceeded to estimate two nested models to test the main direct effects and the moderation effect in order to verify the hypotheses. To test for interaction effects using PLS, we performed a hierarchical process to compare the results of two models: one without and one with the interaction construct following the product approach (Chin et al., 2003). All variables were mean-centred to minimise any multicollinearity threat (Aiken and West, 1991). First, the model was estimated only with the interviewees' demographic variables (i.e. sex and age), that work as control variables. The results showed that neither of these two variables has a significant effect on intention to buy using a mobile $\operatorname{app}\left(\beta_{\text {sex }}=0.028 ; t\right.$-Stat $=0.60 ; \beta_{\text {age }}=-0.097 ; t$-Stat $\left.=0.28\right)$. Secondly, the main effects of focussed attention $(\beta=0.190 * * ;$-Stat $=5.78)$, shopping enjoyment $\left(\beta=0.352^{* *} ; t\right.$-Stat $\left.=10.82\right)$, socialness $(\beta=0.107 * * ; t$-Stat $=2.72)$, shopping gamification $\left(\beta=0.234^{* *} ; t\right.$-Stat $\left.=5.47\right)$, shopping engagement $\left(\beta=0.327^{* *} ; t\right.$-Stat $\left.=10.60\right)$ and previous online shopping experience $\left(\beta=0.451^{* * ;} t\right.$-Stat $\left.=14.32\right)$ on intention to buy using a mobile app were estimated, including the control variables $-i$.e. age $(\beta=0.015$; $t$ Stat $=0.58) ; \operatorname{sex}(\beta=-0.025 ; t$-Stat $=1.04)($ see Table 6$)$.

\begin{tabular}{|c|c|c|c|c|c|c|c|c|c|c|}
\hline \multicolumn{10}{|c|}{ Correlations between constructs } & \\
\hline & AGE & FA & INTBM & EXP & SEX & ENG & ENJ & GAME & SOC & \\
\hline AGE (control) & 1 & & & & & & & & & \\
\hline & -0.087 & 0.842 & & & & & & & & \\
\hline INTBM & -0.016 & 0.238 & 0.820 & & & & & & & \\
\hline EXP & -0.001 & 0.141 & 0.570 & 1 & & & & & & \\
\hline SEX (control) & -0.002 & -0.168 & -0.02 & 0.038 & 1 & & & & & \\
\hline $\mathrm{ENG}$ & -0.094 & 0.496 & 0.500 & 0.371 & -0.05 & 0.833 & & & & \\
\hline ENJ & -0.078 & 0.372 & 0.550 & 0.404 & -0.106 & 0.589 & 0.851 & & & Table 4. \\
\hline GAME & -0.170 & 0.532 & 0.320 & 0.269 & -0.009 & 0.569 & 0.473 & 0.845 & & Descriptive statistics \\
\hline $\mathrm{SOC}$ & -0.125 & 0.473 & 0.430 & 0.313 & -0.092 & 0.528 & 0.523 & 0.631 & 0.820 & and scale correlations \\
\hline
\end{tabular}

\begin{tabular}{lccccccccr}
\hline & AGE & FA & INTBM & EXP & SEX & ENG & ENJ & GAME & SOC \\
AGE (control) & & & & & & & & & \\
FA & 0.091 & & & & & & & & \\
INTBM & 0.030 & 0.281 & & & & & & & \\
EXP & 0.001 & 0.153 & 0.624 & & & & & & \\
SEX (control) & 0.002 & 0.177 & 0.031 & 0.038 & & & & & \\
ENG & 0.105 & 0.588 & 0.609 & 0.416 & 0.058 & & & & Table 5. \\
ENJ & 0.082 & 0.413 & 0.638 & 0.428 & 0.111 & 0.694 & & & \\
GAME & 0.176 & 0.579 & 0.369 & 0.281 & 0.015 & 0.672 & 0.515 & & (discriminant validity \\
SOC & 0.137 & 0.548 & 0.516 & 0.341 & 0.102 & 0.653 & 0.600 & 0.719 & (HT) \\
& & & & & & & & & \\
\end{tabular}

Shopping and Gamification 
IJRDM

49,7
In the last stage, the two-way interaction effect of shopping engagement $x$ previous online shopping experience was added (see Table 6 and Figure 2). In this last estimation phase, a positive and significant link between shopping gamification and shopping engagement $\left(\beta=0.241^{* *} ; t\right.$-Stat $\left.=5.46\right)$ emerged, confirming $\mathrm{H}_{1}$.

\section{2}

Table 6.

Structural model

(direct and interaction effects on intention to buy mobile)

\section{Models}

Direct effects

Control variables

Age $\rightarrow$ Intention to buy using a mobile app

Sex $\rightarrow$ Intention to buy using a mobile app

Main effects

Focussed attention $\rightarrow$ Shopping engagement

Shopping enjoyment $\rightarrow$ Shopping engagement

Socialness $\rightarrow$ Shopping engagement

Shopping gamification $\rightarrow$ Shopping

engagement

Shopping engagement $\rightarrow$ Intention to buy

using a mobile app

Previous online shopping experience $\rightarrow$

Intention to buy using a mobile app

Interaction effect

Previous online shopping experience $\mathrm{x}$

Shopping engagement $\rightarrow$ Intention to buy

using a mobile app

$R^{2}$ (intention to buy using a mobile app)

$\Delta R^{2}$

SRMR

NFI

Note(s): *: $p<0.05 ; * *: p<0.01$

$\begin{array}{rrrrrr}-0.097 & 0.276 & 0.015 & 0.58 & 0.013 & 0.48 \\ 0.028 & 0.600 & -0.025 & 1.04 & -0.010 & 0.41 \\ & & & & & \\ & & 0.190^{* *} & 5.78 & 0.200^{* *} & 5.73 \\ & & 0.352^{* *} & 10.82 & 0.351^{* *} & 9.97 \\ & 0.107^{* *} & 2.72 & 0.094^{*} & 2.29 \\ & & 0.234^{* *} & 5.47 & 0.241^{* * *} & 5.46 \\ & & & & & \\ & & 0.327^{* *} & 10.60 & 0.333^{* *} & 9.92 \\ & & & & & \\ & & & & & \\ & & & & & \\ & & & & 0.063^{* * *} & 13.21 \\ & & & & & \\ & 0.010 & & 0.420 & & \\ & & & 0.410 & & 0.494 \\ & & & 0.055 & & 0.074 \\ & & & 0.873 & & 0.056 \\ & & & & & \end{array}$

Model $1 \quad$ Model $2 \quad$ Model 3

\begin{tabular}{lllllll}
$\beta$ & $t$ & $\beta$ & $t$ & $\beta$ & $t$ \\
\hline
\end{tabular}

Figure 2.

Structural model (direct and interaction effects on intention to buy mobile)

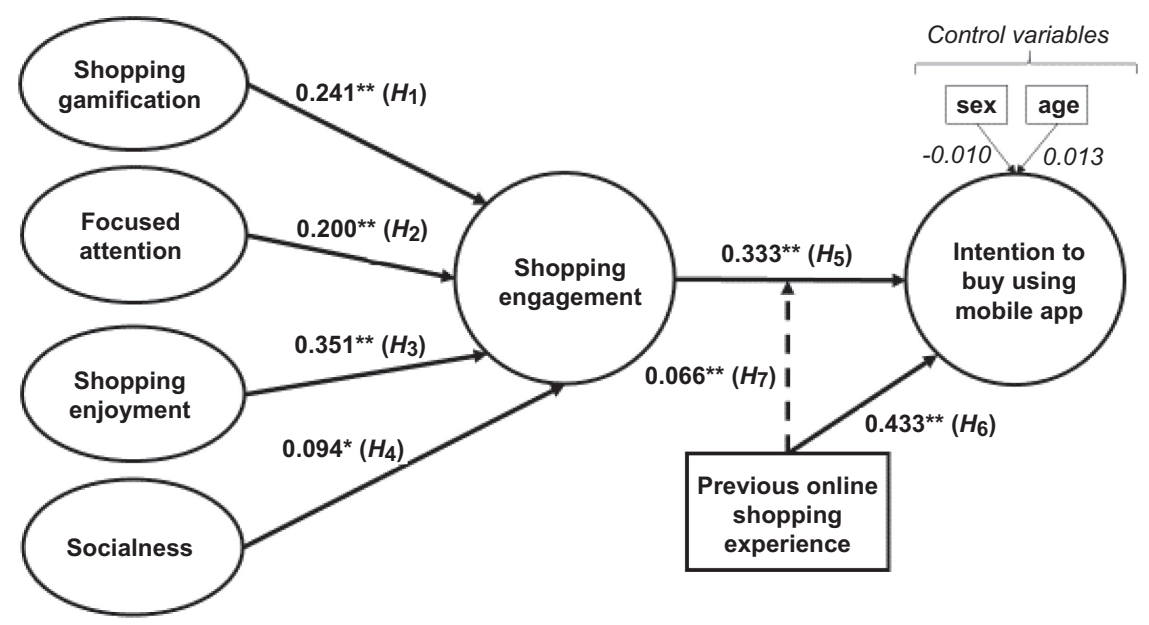

Note(s): Fit indices: $R 2=0.494 ;$ SRMR $=0.056 ; \mathrm{NFI}=0.872$

$$
\text { *: } p<0.05 \text {; *: } p<0.01
$$


The results also showed a direct effect, and significant at least at 0.05 level, of focussed attention $(\beta=0.200 * * ; t$-Stat $=5.73)$, shopping enjoyment $\left(\beta=0.351^{* * ;} t\right.$-Stat $\left.=9.97\right)$ and socialness $(\beta=0.094 *$; $t$-Stat $=2.29)$ on shopping engagement, which allow us to confirm $\mathrm{H}_{2}-\mathrm{H}_{4}$. Moreover, shopping engagement significantly influenced the intention to buy using a mobile app $\left(\beta=0.333^{* *} ; t\right.$-Stat $\left.=9.92\right)$; hence, $\mathrm{H}_{5}$ can be confirmed. With respect to previous online shopping experience, there was a positive and significant effect on intention to buy using a mobile app $\left(\beta=0.433^{* *} ; t\right.$-Stat $\left.=13.21\right)$, confirming $\mathrm{H}_{6}$.

With regard to the effect of interaction, shopping engagement $\mathrm{x}$ shopping experience had a significant, positive influence on the shopping intention using a mobile app $\left(\beta=0.066^{* *}\right.$; $t$-Stat $=2.62$ ). In order to determine the contribution of the interaction term, we calculated the effect size to reflect the increase of $R^{2}$. Based on Cohen (1988), the effect size was $f^{2}=(0.494-$ $0.420) /(1-0.494)=0.146$. We can conclude that the interaction is deemed to be moderate (Cohen, 1988). Thus, $\mathrm{H}_{7}$ is supported. For a deeper understanding, this effect is shown in Figure 3.

\section{Conclusion and implications}

This study is one of the first attempts to empirically analyse the effects of gamified elements in non-game contexts, with a specific focus on the mobile shopping experience. Although the recent marketing literature has turned the spotlight on the positive effect of gamification on consumer behaviour (Hamari et al., 2014), scholars call for more studies providing empirical evidence of the role played by gamification within a wider range of marketing domains (Insley and Nunan, 2014; Poncin et al., 2017). To this aim, this study explores gamification in the mobile shopping experience, when a multifunctional retailing app potentiated with game and social mechanics, is used, namely WeChat. The development of new technologies, the spread of new communication and retailing channels, as well as the increasing availability of innovative mobile, handled and wearable devices are changing consumers' habits. This is increasingly true in China, where a multitude of multifunctional apps is providing a potentiated shopping experience compared to the one provided in Western countries.

Our results confirm previous findings even in the retailing context. Thus, for example, we found that shopping gamification is one of the main motivations driving shopping engagement and indirectly impacting on consumers' intention to buy using a mobile app (Insley and Nunan, 2014; Hofacker et al., 2016; Poncin et al., 2017). Moreover, our findings

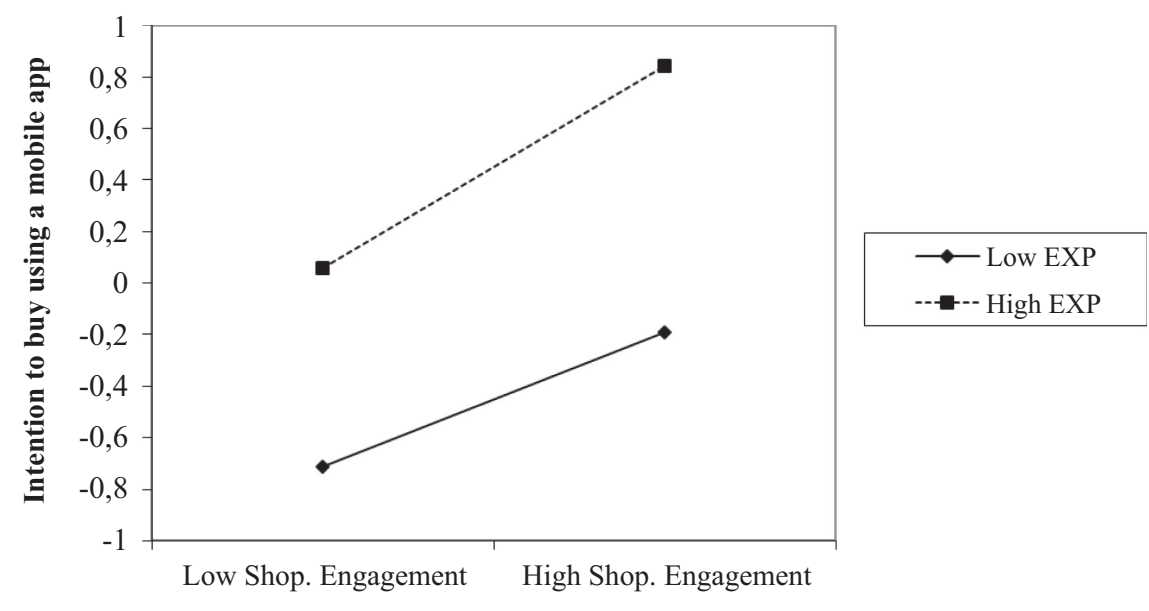

Shopping and Gamification
Figure 3. Moderation effect of previous online shopping experience on shopping engagement-intention to buy using a mobile app 
IJRDM

49,7

934

contribute to extant literature widening existing academic knowledge on the intensity of the effects exerted by other intrinsic motivations impacting on the engagement-intention to buy path, as suggested by Deterding et al. (2011a, b). First, we confirm the positive relationship between socialness and engagement identified by Rodriegues et al. (2016). Second, when a retailing app is investigated, both shopping enjoyment (e.g. De Canio et al., 2019) and focussed attention (e.g. Herzig et al., 2012) play a positive and relevant role in determining shopping engagement.

Concerning the previous online shopping experience, results confirm its dual role in influencing consumers' buying intentions using a mobile app. First, results settle that when consumers have expertise with the online channel, and in particular, with the mobile device, and accordingly they know where and how to buy online, they are more willing to use the app for shopping (e.g. Park and Stoel, 2005). Second, while previous studies have verified the moderating effect of the previous online shopping experience between different antecedents and the intention to buy online, to the best of our knowledge no previous study has investigated its moderating role on the engagement-intention path. This result adds a further piece of knowledge to the nascent literature on the use of game mechanics in retailing. Indeed, going further the results of Poncin et al. (2017) finding that the inclusion of simultaneous game-mechanics may be too complicated for the users when the challenge is too complex, making the overall gamification effect negative, our results show that when a multifunctional app is investigated, the previous online shopping experience both supports shopping intention and amplifies the positive impact of engagement on shopping intentions. Thus, controlling for the previous online shopping experience, it is possible to include more game mechanics simultaneously. Accordingly, our results provide a first answer to the RQ4 posed by Hofacker $e t$ al. (2016). Results provide empirical evidence that there is no demographic effect (i.e. gender and age) when gamification is studied as antecedent of mobile shopping engagement.

Findings offer some relevant implications also for practitioners. First, when retailers aim to introduce gamified mechanics into their mobile retailing apps, they should introduce game mechanics by challenge levels, similarly to what happen in video games. As done by WeChat, the app is introducing functionalities step by step; this approach is enabling the app to be China's first multifunctional app on which users spend over $360 \mathrm{~min} /$ day on it. Likewise the Chinese experience, online retailers, above all Western ones, should innovate their online stores with non-game tools to differentiate their offer and engage consumers. In this sense, as highlighted in the literature (Insley and Nunan, 2014), being able to leverage on consumers' intrinsic motivations can lead to acquiring consumers' preferences. Further, implementing communication campaigns aimed at clarifying and better explain how consumers might purchase online, companies can increase the level of online channels knowledge of their actual and prospective customers, reinforcing their engagement, enriching the previous online shopping experience and increasing their proneness to online purchase through mobile devices. Operationally, this can be purposed stressing the "shopping game" effect and arranging e-commerce web-sites and retailing platforms with funny and engaging tasks (e.g. review or rate products), competitions, bonuses and credits collections - better if based on an award-winning effect, boosting the self-empowerment sentiment of people and their feeling to be successful as well as increasing their level of amusement and pleasure. Similar tools have been successfully implemented in online banking transferring a quota of transactions, typically carried by consumers in banks, on mobile applications. Mobile applications potentiated with gamified elements can be then more flexible, convenient, interactive and engaging. Finally, as the social influence, as well as the influence of family members and relatives is very important for Chinese, it is mandatory for digital players to settle in a coherent way gamification and marketing strategies. Indeed, gamification is part of a wider company's strategy to improve the platform-user interaction, and social and gamified cues 
should be coherently implemented by the platform in order to clearly impact on final users. Otherwise, gamification may lead to market strategies distortion.

\section{Limitations and directions for further research}

Despite the main contributions provided by this paper, further research exploring the role of gamified dynamics in the retailing sector is required. First, this study focusses on the intrinsic motives behind the intention to buy using a mobile app. Further studies should compare intrinsic and extrinsic motivations to understand if is more valuable for retailers to compete with price strategies or provide social, enjoyable and gamified shopping experiences.

Amongst the main limitations of this study, the use of cross-section data does not allow us to generalise results of causality between constructs. Future studies might also replicate the theoretical model considering other multifunctional apps and/or national contexts. The study took into consideration WeChat as the gamified retailing app. Nevertheless, in China, there are several other multifunctional apps allowing gamified retailing experiences. Accordingly, in future studies a comparison between multifunctional apps should be proposed to understand which gamified mechanic is more relevant in the retailing context. Future results should also be evaluated in the light of the overall interaction strategy proposed by the platform. As found by Hamari (2013) depending on the utilitarian vs hedonic function of the platform, gamification may have different impacts. Accordingly, further studies should confirm and deepen the proposed model bringing our results and expanding their coverage, for example in the area of e-commerce, sharing economy and social networking. Similarly, China is the place with the highest percentage of mobile shoppers and a country with a long tradition in video games and individual interaction with technological tools. The application of the proposed theoretical model comparing apps available in East and West countries can broaden the generalisability of our results.

Further, the emerging gamifying mechanics, identified in Table 1 show that several opportunities exist with different implications for platforms, requiring further empirical evidence on their value in companies' strategies.

Finally, future research should investigate the gamification concept in retailing apps enhanced by virtual tour and augmented reality (Caboni and Hagberg, 2019). Indeed, combine increasing interactive technologies (i.e. virtual and augmented reality) with game design elements can stimulate intrinsic motivations and generate consumer engagement in non-game contexts. Accordingly, game mechanics can profitably be combined with augmented mechanics.

\section{ORCID iDs}

Francesca De Canio (Dhttp://orcid.org/0000-0003-4658-282X

Maria Fuentes-Blasco Dhttp://orcid.org/0000-0002-7082-7068

Elisa Martinelli (Dhttp://orcid.org/0000-0002-7429-8829

\section{References}

Agarwal, R. and Karahanna, E. (2000), "Time flies when you're having fun: cognitive absorption and beliefs about information technology usage", MIS Quarterly, Vol. 24 No. 4, pp. 665-694.

Aiken, L. and West, S. (1991), Multiple Regression: Testing and Interpreting Interactions, Sage, Newbury Park, CA.

Anderson, J.C. and Gerbing, D.W. (1988), "Structural equation modeling in practice: a review and recommended two-step approach”, Psychological Bulletin, Vol. 103 No. 3, pp. 411-423.

Arnold, M. and Reynolds, K. (2003), "Hedonic shopping motivations", Journal of Retailing, Vol. 79 No. 2, pp. 77-95. 
IJRDM

49,7

936
Arnold, M.J. and Reynolds, K.E. (2003), "Hedonic shopping motivations", Journal of Retailing, Vol. 79 No. 2, pp. 77-95.

Beatty, S.E. and Ferrell, M.E. (1998), "Impulse buying: modeling its precursors", Journal of Retailing, Vol. 74 No. 2, pp. 169-191.

Blazquez-Cano, M.B., Perry, P., Ashman, R. and Waite, K. (2017), "The influence of image interactivity upon user engagement when using mobile touch screens", Computers in Human Behavior, Vol. 77, pp. 406-412.

Blohm, I. and Leimeister, J.M. (2013), "Gamification”, Business and Information Systems Engineering, Vol. 5 No. 4, pp. 275-278.

Brodie, R.J., Hollebeek, L.D. and Smith, S.D. (2011), "Engagement: an important bridging concept for the emerging SD logic lexicon", Proceedings of 2011 Naples Forum on Service.

Caboni, F. and Hagberg, J. (2019), "Augmented reality in retailing: a review of features, applications and value", International Journal of Retail and Distribution Management, Vol. 47 No. 11, pp. 1125-1140.

Castañeda, J.A., Muñoz-Leiva, F. and Luque, T. (2007), "Web acceptance model (WAM): moderating effects of user experience", Information and Management, Vol. 44 No. 4, pp. 384-396.

Chin, W.W., Marcolin, B.L. and Newsted, P.N. (2003), "A partial least squares latent variable modeling approach for measuring interaction effects: results from a Monte Carlo simulation study and an electronic-mail emotion/adoption study", Information Systems Research, Vol. 14 No. 2, pp. 189-217.

Chin, W.W., Thatcher, J.B., Wright, R.T. and Steel, D. (2013), "Controlling for common method variance in PLS analysis: the measured latent marker variable approach", in Abdi, H., Chin, W.W., Esposito Vinzi, V., Russolillo, G. and Trinchera, L. (Eds), New Perspectives in Partial Least Squares and Related Methods, Springer, New York.

China Internet Watch (2019), “Top mobile shopping apps in China 2019: penetration, usage, user profile", available at: https://www.chinainternetwatch.com/tag/mobile-shopping/ (accessed 18 August 2019).

Choi, Y.K., Yoon, S. and Lacey, H.P. (2013), "Online game characters' influence on brand trust: selfdisclosure, group membership, and product type", Journal of Business Research, Vol. 66 No. 8, pp. 996-1003.

Chong, A.Y.L. (2013), "A two-staged SEM-neural network approach for understanding and predicting the determinants of m-commerce adoption", Expert Systems with Applications, Vol. 40 No. 4, pp. 1240-1247.

Cohen, J. (1988), Statistical Power Analysis for the Behavioral Sciences, 2nd ed., Lawrence Erlbaum Associates, Hillsdale, NY.

Davis, F.D., Bagozzi, R.P. and Warshaw, P.R. (1992), "Extrinsic and intrinsic motivation to use computers in the workplace", Journal of Applied Social Psychology, Vol. 22 No. 14, pp. 1111-1132.

Davis, F.D. (1986), A Technology Acceptance Model for Empirically Testing New End-User Information Systems: Theory and Results, Doctoral Dissertation submitted to the Sloan School of Management, Massachusetts Institute of Technology.

De Canio, F., Martinelli, E., Pellegrini, D. and Nardin, G. (2019), "Influencing shopping engagement across channels: the role of store environment", in Advances in National Brand and Private Label Marketing, Springer, Cham, pp. 106-113.

Deterding, S., Dixon, D., Khaled, R. and Nacke, L. (2011a), "From game design elements to gamefulness: defining gamification", Proceedings of the 15th international academic MindTrek conference: Envisioning future media environments, pp. 9-15.

Deterding, S., Khaled, R., Nacke, L.E. and Dixon, D. (2011b), "Gamification: toward a definition”, CHI 2011 Gamification Workshop Proceedings, Canada, Vancouver BC, Vol. 12. 
Domínguez, A., Saenz-De-Navarrete, J., De-Marcos, L., FernáNdez-Sanz, L., PagéS, C. and MartîNezHerrálz, J.J. (2013), "Gamifying learning experiences: practical implications and outcomes", Computers and Education, Vol. 63, pp. 380-392.

Eisingerich, A.B., Marchand, A., Fritze, M.P. and Dong, L. (2019), "Hook vs. hope: how to enhance customer engagement through gamification", International Journal of Research in Marketing, Vol. 36 No. 2, pp. 200-215.

Fang, P. (2019), "Understanding the Chinese game industry", available at: https://www.vengaglobal. $\mathrm{com} / \mathrm{blog} /$ understanding-the-chinese-game-industry/ (accessed 11 March 2020).

Fishbein, M. and Ajzen, I. (1980), Understanding Attitudes and Predicting Social Behavior, Prenticehall, Englewood Cliffs, NJ.

Flavián, C., Ibáñez-Sánchez, S. and Orús, C. (2019), "The impact of virtual, augmented and mixed reality technologies on the customer experience", Journal of Business Research, Vol. 100, pp. 547-560.

Fornell, C. and Larcker, D.F. (1981), "Evaluating structural equation models with unobservable variables and measurement error", Journal of Marketing Research, Vol. 18 No. 1, pp. 39-50.

Fullerton, T. (2014), Game Design Workshop: A Playcentric Approach to Creating Innovative Games, CRC press, CRC press, London, UK.

Gatautis, R., Vitkauskaite, E., Gadeikiene, A. and Piligrimiene, Z. (2016), "Gamification as a mean of driving online consumer behaviour: SOR model perspective”, Engineering Economics, Vol. 27 No. 1, pp. 90-97.

Giovanis, A., Assimakopoulos, C. and Sarmaniotis, C. (2018), "Adoption of mobile self-service retail banking technologies", International Journal of Retail and Distribution Management, Vol. 47 No. 9, pp. 894-914.

Goldstein, D.G. and Gigerenzer, G. (2002), "Models of ecological rationality: the recognition heuristic", Psychological Review, Vol. 109 No. 1, pp. 75-90.

Hair J.F., Jr., M, Hult, G.T., Ringle, C., Sarstedt, M., Castillo Apraiz, J. and Cepeda Carrián, G. A.Roldán, J.L. (2019), Manual de Partial Least Squares Structural Equation Modeling (PLS-SEM), 2nd ed., OmniaScience.

Hamari, J., Koivisto, J. and Sarsa, H. (2014), "Does gamification work?-a literature review of empirical studies on gamification", in 47th Hawaii International Conference on System Sciences, pp. 3025-3034.

Hamari, J. (2013), "Transforming homo economicus into homo ludens: a field experiment on gamification in a utilitarian peer-to-peer trading service", Electronic Commerce Research and Applications, Vol. 12 No. 4, pp. 236-245.

Henseler, J., Ringle, C.M. and Sinkovics, R.R. (2009), Advances in International Marketing, Emerald Group Publishing, Bingley.

Henseler, J., Ringle, C.M. and Sarstedt, M. (2015), "A new criterion for assessing discriminant validity in variance-based structural equation modeling", Journal of the Academy of Marketing Science, Vol. 43 No. 1, pp. 115-135.

Herzig, P., Strahringer, S. and Ameling, M. (2012), "Gamification of ERP systems-Exploring gamification effects on user acceptance constructs", in Multikonferenz Wirtschaftsinformatik, GITO Braunschweig, pp. 793-804.

Higgins, E.T. (2006), "Value from hedonic experience and engagement", Psychological Review, Vol. 113 No. 3, p. 439.

Hofacker, C.F., De Ruyter, K., Lurie, N.H., Manchanda, P. and Donaldson, J. (2016), "Gamification and mobile marketing effectiveness", Journal of Interactive Marketing, Vol. 34, pp. 25-36.

Holbrook, M.B., Chestnut, R.W., Oliva, T.A. and Greenleaf, E.A. (1984), "Play as a consumption experience: the roles of emotions, performance, and personality in the enjoyment of games", Journal of Consumer Research, Vol. 11 No. 2, pp. 728-739. 
IJRDM

49,7

938

Holopainen, J. (2011), Foundations of Gameplay, Blekinge Institute of Technology, Karlskrona.

Hsu, C.L. and Chen, M.C. (2018), "How does gamification improve user experience? An empirical investigation on the antecedences and consequences of user experience and its mediating role", Technological Forecasting and Social Change, Vol. 132, pp. 118-129.

Hsu, C.L. and Lu, H.P. (2004), "Why do people play on-line games? An extended TAM with social influences and flow experience", Information and Management, Vol. 41 No. 7, pp. 853-868.

Huang, J.H., Lin, Y.R. and Chuang, S.T. (2007), "Elucidating user behavior of mobile learning", The Electronic Library, Vol. 25 No. 5, pp. 585-598.

Huotari, K. and Hamari, J. (2012), "Defining gamification: a service marketing perspective”, Proceeding of the 16th International Academic MindTrek Conference, pp. 17-22.

Hwang, J. and Choi, L. (2020), "Having fun while receiving rewards?: exploration of gamification in loyalty programs for consumer loyalty”, Journal of Business Research, Vol. 106, pp. 365-376.

Insley, V. and Nunan, D. (2014), "Gamification and the online retail experience", International Journal of Retail and Distribution Management, Vol. 42 No. 5, pp. 340-351.

Johnson, K.K., Kim, H.Y., Mun, J.M. and Lee, J.Y. (2015), "Keeping customers shopping in stores: interrelationships among store attributes, shopping enjoyment, and place attachment", The International Review of Retail, Distribution and Consumer Research, Vol. 25 No. 1, pp. 20-34.

Katz, J.E. and Rice, R.E. (2002), Social Consequences of Internet Use: Access, Involvement, and Interaction, MIT press, Cambridge, MA.

Kim, E., Lin, J.S. and Sung, Y. (2013), “To app or not to app: engaging consumers via branded mobile apps", Journal of Interactive Advertising, Vol. 13 No. 1, pp. 53-65.

Kumar, J. (2013), "Gamification at work: designing engaging business software", in International Conference of Design, User Experience, and Usability, Springer, Berlin, Heidelberg, pp. 528-537.

Lazar, J. and Preece, J. (2002), "Social considerations in online communities: usability, sociability, and success factors", in Cognition in the Digital World, Lawrence Erlbaum Associates Inc. Publishers, Mahwah, NJ.

Lee, M.C. and Tsai, T.R. (2010), "What drives people to continue to play online games? An extension of technology model and theory of planned behavior", International Journal of Human-Computer Interaction, Vol. 26 No. 6, pp. 601-620.

Lin, J.C.C. (2007), "Online stickiness: its antecedents and effect on purchasing intention”, Behaviour and Information Technology, Vol. 26 No. 6, pp. 507-516.

Lynkova, D. (2019), "Top gamification statistics of 2020: next level gaming", available at: https:// review42.com/gamification-statistics/ (accessed 3 March 2020).

Malone, T.W. (1980), What Makes Things Fun to Learn? A Study of Intrinsically Motivating Computer Games, Doctoral dissertation, ProQuest Information and Learning, Palo Alto, CA: Xerox.

Malone, T.W. (1981), "Toward a theory of intrinsically motivating instruction”, Cognitive Science, Vol. 5 No. 4, pp. 333-369.

Novak, T.P., Hoffman, D.L. and Yung, Y.F. (2000), "Measuring the customer experience in online environments: a structural modeling approach”, Marketing Science, Vol. 19 No. 1, pp. $22-42$.

Nunnally, J.C. and Bernstein, I.H. (1994), Psychometric Theory, 3rd ed., Mc-Graw Hill, New York.

O'Brien, H.L. and Toms, E.G. (2008), "What is user engagement? A conceptual framework for defining user engagement with technology", Journal of the American Society for Information Science and Technology, Vol. 59 No. 6, pp. 938-955.

O'brien, H.L. and Toms, E.G. (2013), "Examining the generalizability of the user engagement scale (UES) in exploratory search", Information Processing and Management, Vol. 49 No. 5, pp. 1092-1107. 
O'Brien, H.L. (2010), "The influence of hedonic and utilitarian motivations on user engagement: the case of online shopping experiences", Interacting with Computers, Vol. 22 No. 5, pp. 344-352.

Overby, J.W. and Lee, E.J. (2006), "TThe effects of utilitarian and hedonic online shopping value on consumer preference and intentions", Journal of Business Research, Vol. 59 No. 10/11, pp. 1160-1166.

Pappas, I.O., Pateli, A.G., Giannakos, M.N. and Chrissikopoulos, V. (2014), "Moderating effects of online shopping experience on customer satisfaction and repurchase intentions", International Journal of Retail and Distribution Management, Vol. 42 No. 3, pp. 187-204.

Park, J. and Stoel, L. (2005), "Effect of brand familiarity, experience and information on online apparel purchase", International Journal of Retail and Distribution Management, Vol. 33 No. 2, pp. 148-160.

Perugini, M. and Bagozzi, R.P. (2001), "The role of desires and anticipated emotions in goal-directed behaviours: broadening and deepening the theory of planned behavior", British Journal of Social Psychology, Vol. 40 No. 1, pp. 79-98.

Piotrowicz, W. and Cuthbertson, R. (2014), "Introduction to the special issue information technology in retail: toward omnichannel retailing", International Journal of Electronic Commerce, Vol. 18 No. 4, pp. 5-16.

Ploll, U. and Stern, T. (2020), "From diet to behaviour: exploring environmental-and animal-conscious behaviour among Austrian vegetarians and vegans", British Food Journal, Vol. 122 No. 11, pp. 3249-3265.

Poncin, I., Garnier, M., Mimoun, M.S.B. and Leclercq, T. (2017), "Smart technologies and shopping experience: are gamification interfaces effective? The case of the Smartstore", Technological Forecasting and Social Change, Vol. 124, pp. 320-331.

QP Software (2020), "What can you do with WeChat?", available at: https://qpsoftware.net/blog/allwechat-features-2020 (accessed 5 December 2020).

Ringle, C.M., Wende, S. and Becker, J.M. (2015), "SmartPLS 3", Boenningstedt: SmartPLS GmbH, available at: http://www.smartpls.com.

Robson, K., Plangger, K., Kietzmann, J., McCarthy, I. and Pitt, L. (2014), "Understanding gamification of consumer experiences", Advances in Consumer Research, Vol. 42, pp. 352-356.

Rodrigues, L.F., Oliveira, A. and Costa, C.J. (2016), "Playing seriously-How gamification and social cues influence bank customers to use gamified e-business applications", Computers in Human Behavior, Vol. 63, pp. 392-407.

Seaborn, K. and Fels, D.I. (2015), "Gamification in theory and action: a survey”, International Journal of Human-Computer Studies, Vol. 74, February, pp. 14-31.

Shang, R.A., Chen, Y.C. and Shen, L. (2005), "Extrinsic versus intrinsic motivations for consumers to shop on-line", Information and Management, Vol. 42 No. 3, pp. 401-413.

Siregar, Y. and Kent, A. (2019), "Consumer experience of interactive technology in fashion stores", International Journal of Retail and Distribution Management, Vol. 47 No. 12, pp. 1318-1335.

Steenkamp, J.B.E. and Van Trijp, H.C. (1991), "The use of LISREL in validating marketing constructs", International Journal of Research in Marketing, Vol. 8 No. 4, pp. 283-299.

Thakur, R. (2016), "Understanding customer engagement and loyalty: a case of mobile devices for shopping", Journal of Retailing and Consumer Services, Vol. 32, pp. 151-163.

Tobon, S., Ruiz-Alba, J.L. and García-Madariaga, J. (2020), "Gamification and online consumer decisions: is the game over?”, Decision Support Systems, Vol. 128, pp. 1-13.

Trevino, L.K. and Webster, J. (1992), "Flow in computer-mediated communication: electronic mail and voice mail evaluation and impacts", Communication Research, Vol. 19 No. 5, pp. 539-573.

Tversky, A. and Kahneman, D. (1974), "Judgment under uncertainty: heuristics and biases”, Science, Vol. 185 No. 4157, pp. 1124-1131. 
IJRDM

49,7

940
Van der Heijden, H. (2004), "User acceptance of hedonic information systems”, MIS Quarterly, Vol. 28 No. 4, pp. 695-704.

Van Doorn, J., Lemon, K.N., Mittal, V., Nass, S., Pick, D., Pirner, P. and Verhoef, P.C. (2010), “Customer engagement behavior: theoretical foundations and research directions", Journal of Service Research, Vol. 13 No. 3, pp. 253-266.

Vivek, S.D., Beatty, S.E., Dalela, V. and Morgan, R.M. (2014), “A generalized multidimensional scale for measuring customer engagement”, Journal of Marketing Theory and Practice, Vol. 22 No. 4, pp. 401-420.

Webster, J. and Martocchio, J.J. (1995), "The differential effects of software training previews on training outcomes", Journal of Management, Vol. 21 No. 4, pp. 757-787.

Wolfinbarger, M. and Gilly, M.C. (2001), "Shopping online for freedom, control, and fun”, California Management Review, Vol. 43 No. 2, pp. 34-55.

Yang, Y., Asaad, Y. and Dwivedi, Y. (2017), "Examining the impact of gamification on intention of engagement and brand attitude in the marketing context", Computers in Human Behavior, Vol. 73, pp. 459-469.

\section{Corresponding author}

Francesca De Canio can be contacted at: francesca.decanio@unimore.it

For instructions on how to order reprints of this article, please visit our website: 